\title{
Optimization Design of Drive Head on CBM Vehicle Drill Rig
}

\author{
Zhi Liu \\ Xi'an Research Institute,CCTEG,Xi'an710077,China \\ email:liuzhi030191@sina.com
}

Keywords: CBM Vehicle Drill Rig; Drive Head; Reducer; Matlab Optimal Design

Abstract. This paper introduces the working process and technical parameters of drive head on CBM vehicle drill rig in detail. With structural parameters as design variables, minimum volume as objective function and parameter and checking conditions of single gear transmission axis and gear as constraint conditions, the optimization design model of reducer is established. Based on the optimized design functions of Matlab, the optimization matching of top drive structural parameters is achieved by selecting the sequential quadratic programming as the optimization algorithm. The calculated results provide basic reference for optimization design of reducer.

\section{Introduction}

The reducer is the key part of the drill as the drill pipe rotating dynamic source, the working performance will directly influence the drill operation, the main function is aim at continuously rotation crushing the rock and extending the borehole, which the purpose is relaxed by providing needed torque and rotational speed for drilling pipes and tools[1-2].

\section{Structure Design and Property Parameters of the Drive Head}

The drill drive head is composed of bearing box and reducer. The bearing box is made by steel welded structure. The upper part connects lifting cord tackle, the lower part connects feeding wire ropes, the drive head was done up and down along stretching mast guideway under the action of lifting mechanism[3]. The reducer consists of central axle, bearing, drive gear, hydraulic motor and sealing device. The top of central axle was connected drilling liquid or gas cycle pipe by sealing device, the bottom was connected drill pipe by floating joints. The reducer is first order directly gear transmission, the central axle and drill tools are rotated by two hydraulic motors driving gear along. As Figure 1 shows that searching the best gear transmission design scheme is great significance for improving transmission performance, bearing ability and life, inducing external dimensions and weight, reducing materials consumption. As Table 1 shows that main working parameters of the top drive head.

Tab.1 Main working parameters of Top drive head

\begin{tabular}{cc}
\hline parameter name & parameter value \\
\hline Maxim output torque & $15 \mathrm{kN} \cdot \mathrm{m}$ \\
Output speed & $0-150 \mathrm{r} / \mathrm{min}$ \\
\hline
\end{tabular}




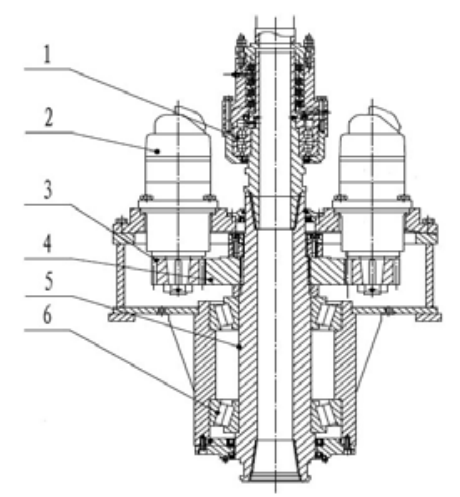

1.bearing 2. hydraulic motor 3.small gear 4.large gear 5. central axle 6.bearing

Fig. 1 Hydraulic top drive rotating device

\section{Mathematics Model Building of the Hydraulic Drive Head}

As Figure 1 shows that the material of the small gear in reducer is $20 \mathrm{Cr}_{2} \mathrm{Ni}_{4}$, the material of the big gear in reducer is $42 \mathrm{CrMo}$, the gear asymmetric layout, unidirectional rotating, seriously impacting and 8 level precision. The material of gear shaft is $35 \mathrm{CrMoA[4].}$

\section{Calculation Process and Methods}

\section{Design Variables}

In order to minimum the volume of the reducer, every part design depends on six aspects of $b, Z_{1}, m, l, d_{Z_{1}}, d_{Z_{2}}$. The corresponding design values are as next formula.

$$
\mathrm{X}=\left[x_{1}, x_{2}, x_{3}, x_{4}, x_{5}, x_{6}\right] \mathrm{T}=\left[b, Z_{1}, m, l, d_{Z_{1}}, d_{Z_{2}}\right]^{T}
$$

Including: $b$-large gear width; $Z_{1}$ —small gear teeth number; $m$ —gear modulus; $l$ —shaft bearing distance; $d_{\mathrm{z} 1}$-active shaft diameter; $d_{\mathrm{z} 2}$-driven shaft diameter.

\section{Objective Function}

For the sake of meeting parts strength and stiffness and saving material, the paper established objective function according to the principle of minimizing the sum of reducer volume. The size of gear and shaft which are parts in shell decides the volume of speed reducer, two groups of small gears is evenly distributed big gear axis as the center line as the Figure 1. The optimization equation could be seen as single-stage bevel gear meshing according to the calculation formula of gear geometry size and the gear structure size, the volume of internal shell could be represented as the sum of the volume of the gear and shaft[5].

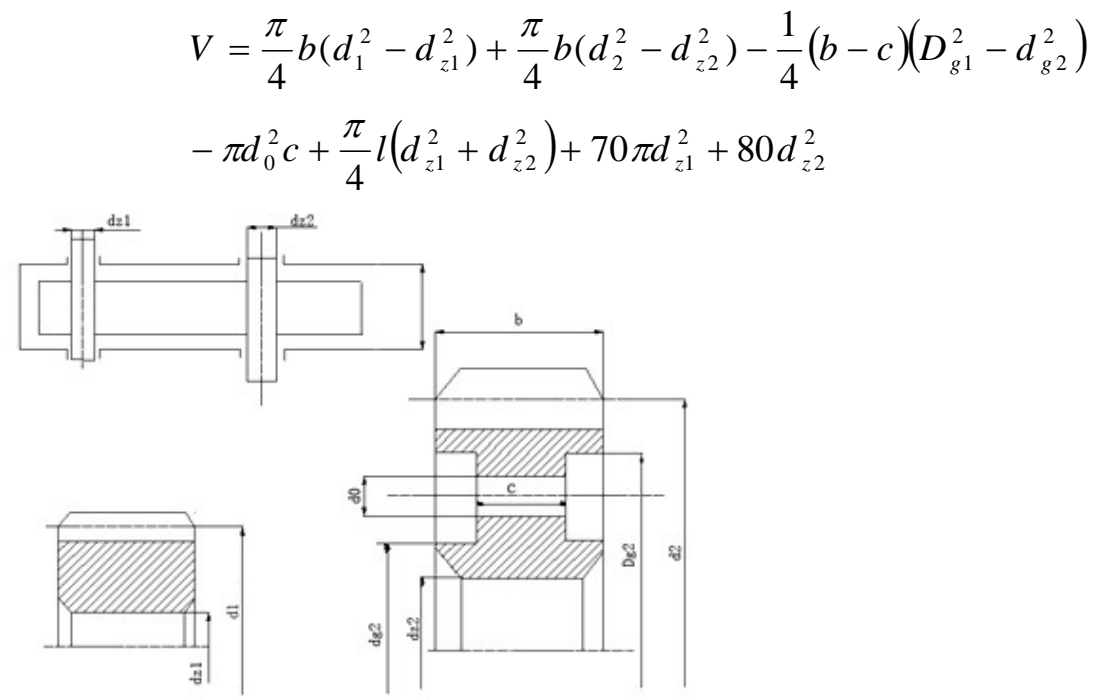

Fig. 2 Single-stage gear meshin 
As the Figure 2 shows that:

$$
d_{1}=m z_{1}, \quad d_{2}=m z_{2}, D_{g 2}=i d_{1}-10 m, d_{g 2}=1.6 d_{z 2}, d_{0}=0.25\left(D_{g 2}-d_{g 2}\right), c=0.2 b
$$

So we put last-written into formula 1 , then finish the objective function:

$$
\begin{aligned}
& f(x)=0.78539 \times\left(4.75 x_{1} x_{2}^{2} x_{3}^{2}+85 x_{1} x_{2} x_{3}^{2}-85 x_{1} x_{3}^{2}+0.92 x_{1} x_{6}^{2}\right. \\
& \left.-x_{1} x_{5}^{2}+0.8 x_{1} x_{2} x_{3} x_{6}-1.6 x_{1} x_{3} x_{6}+x_{4} x_{5}^{2}+x_{4} x_{6}^{2}+280 x_{5}^{2}+320 x_{6}^{2}\right)
\end{aligned}
$$

\section{Constraint Condition}

(1)Hard gear surface was adopted closed transmission system under impact loading, when mode number was $\mathrm{m}=(0.012 \sim 0.018) \mathrm{a}$, and a was central distance between two gears.

$$
\begin{aligned}
& g_{1}(x)=28-x_{2} \leq 0 \\
& g_{2}(x)=x_{2}-42 \leq 0
\end{aligned}
$$

(2)In order to improve transmission stability and increase coincidence degree, mode number was bigger during hard gear surface closed driven seriously impacted.

$$
g_{3}(x)=6-x_{3} \leq 0
$$

(3) Cylindrical gear tooth width modulation coefficient was determined $\psi_{\min } \leq \frac{b}{d_{1}} \leq \psi_{\max }$ by checking the manual, the value $0.9 \leq \psi_{d} \leq 1.4$ was adopted

$$
\begin{aligned}
& g_{4}(x)=0.9-x_{1} /\left(x_{2} x_{3}\right) \leq 0 \\
& g_{5}(x)=x_{1} /\left(x_{2} x_{3}\right)-1.4 \leq 0
\end{aligned}
$$

(4) Considering about the processing technology and the overall size, big dividing circle diameter of gears was $d_{2} \leq 1500 \mathrm{~mm}$ and the small one was $d_{1} \leq 500 \mathrm{~mm}$.

$$
g_{6}(x)=x_{2} x_{3}-500 \leq 0
$$

(5) According to design experience, lord and driven shaft diameter range were $100 \leq d_{z 1} \leq 150$ and $130 \leq d_{z 2} \leq 200$, so constraints for shaft diameter were 10-13.

$$
\begin{aligned}
& g_{7}(x)=100-x_{5} \leq 0 \\
& g_{8}(x)=x_{5}-150 \leq 0 \\
& g_{9}(x)=130-x_{6} \leq 0 \\
& g_{10}(x)=x_{6}-200 \leq 0
\end{aligned}
$$

(6) The supported span length $l$ of shaft according to the structure relationship satisfies $l \geq b+2 \Delta+0.5 d_{\mathrm{z} 2}, \Delta_{\min }$ was the distance between inner surface and bearing.

$$
g_{11}(x)=x_{1}+0.5 x_{6}-x_{4}+40 \leq 0
$$

(7) According to the gear contact stress conditions,

$$
\sigma_{H}=Z_{E} Z_{H} \cdot \sqrt{\frac{2 K T_{1}}{b d_{1}^{2}} \cdot \frac{i+1}{i}} \leq\left[\sigma_{H}\right]
$$

Including: $\mathrm{K}$ - contact strength load coefficient as $\mathrm{K}=3.0 ; Z_{H}$ - coefficient of node area $Z_{H}=2.5 ; Z_{E}$-material coefficient $Z_{E}=189.8 P_{a}{ }^{\frac{1}{2}} ;\left[\sigma_{H}\right]$-Pinion allowable contact stress $\left[\sigma_{H}\right]=600 \mathrm{Mpa} ; d_{1}$-pinion dividing circle diameter $d_{1}=m z_{1}$.

$$
\sigma_{H}=1.759 \times 10^{6} \times \sqrt{\frac{1}{b\left(m Z_{1}\right)^{2}}} \leq\left[\sigma_{H}\right]
$$

Then finished,

$$
g_{12}(x)=1.759 \times 10^{6} /\left(\mathrm{x}_{2} x_{3} \sqrt{x_{1}}\right)-600 \leq 0
$$

(8) According to the condition of tooth root bending strength,

$$
\sigma_{F}=\frac{2 K^{\prime} T_{1}}{b d_{1} m Y} \leq\left[\sigma_{F}\right]
$$


Including: $K^{\prime}-$ comprehensive coefficient of bending strength, $K^{\prime}=2.5 ;\left[\sigma_{F}\right]$ 一the allowable bending stress, $\left[\sigma_{F}\right]_{1}=606 \mathrm{Mpa},\left[\sigma_{F}\right]_{2}=564 \mathrm{Mpa}$; $\mathrm{Y}_{1}$ - the small gear tooth shape coefficient, $\mathrm{Y}_{1}=0.169+0.00666 \mathrm{Z}_{1}-0.0000854 \mathrm{Z}_{1}, \mathrm{Y}_{2}$ - the large gear tooth shape coefficient, $\mathrm{Y}_{2}=0.2824+0.0003539\left(i Z_{1}\right)-0.000001576\left(i Z_{1}\right)^{2}$.

For the small gear tooth root bending strength

$$
\sigma_{F 1}=\frac{2 K^{\prime} T_{1}}{b d_{1} m Y_{1}} \leq\left[\sigma_{F}\right]_{1}
$$

Then finished

$$
g_{13}(x)=\frac{8.59 \times 10^{6}}{x_{3}{ }^{2} x_{2} x_{1}\left(0.169+0.006666 x_{2}-0.0000854 x_{2}^{2}\right)}-606 \leq 0
$$

For the large gear tooth root bending strength

Then finished

$$
\sigma_{F 2}=\frac{2 K^{\prime} T_{1}}{\psi_{d} d_{1}^{2} m Y_{2}} \leq\left[\sigma_{F}\right]_{2}
$$

$$
g_{14}(x)=\frac{8.59 \times 10^{6}}{x_{3}{ }^{2} x_{2} x_{1}\left(0.2824+0.0010617 x_{2}-0.000014184 x_{2}^{2}\right)}-564 \leq 0
$$

(9) After checking the manual, the allowable deflection of the installed gear shaft was

$$
\frac{F_{n} l^{3}}{48 E I} \leq 0.03 x_{3}
$$

Including $F_{n}=\frac{2 T_{1}}{m z_{1} \cos \alpha} ; \mathrm{E}$-Elastic Modulus, $\mathrm{E}=2 \times 10^{5} \mathrm{~N} / \mathrm{mm}^{2} ; \alpha$-pressure angle, $\alpha=20^{\circ} ; \mathrm{I}-$ moment of axis inertia, circular cross section $\mathrm{I}_{1}=\pi d_{\mathrm{Z1}}{ }^{4} / 64=\pi x_{5}{ }^{4} / 64$, circular truncation $\mathrm{I}_{2}=\pi d_{Z_{2}}{ }^{4}\left(1-(0.5)^{4}\right) / 64$.

Stiffness constraints of drive shaft

Stiffness constraints of lord shaft

$$
g_{15}(x)=\frac{24.4 x_{4}^{3}}{\pi x_{2} x_{3} x_{5}^{4}}-0.03 x_{3} \leq 0
$$

(10) Bending strength conditions of shaft

$$
g_{16}(x)=\frac{25.9 x_{4}^{3}}{\pi x_{2} x_{3} x_{6}^{4}}-0.03 x_{3} \leq 0
$$

$$
\sigma_{w}=\frac{\sqrt{M^{2}+\left(\alpha_{1} T\right)^{2}}}{W} \leq\left[\sigma_{-1}\right]
$$

Including: $\mathrm{M}$-bending moment of shaft, $\mathrm{M}=\frac{T_{1} l}{m z_{1} \cos \alpha} ; \alpha_{1}$ - the torque coefficient of correction, $\alpha_{1}=0.3 ; \mathrm{W}_{1}$ - bending section coefficient of shaft, drive shaft was the real axis $\mathrm{W}_{1}=0.1 d_{z 1}^{3}=0.1 x_{5}^{3}$, lord shaft was empty axis $w_{2}=0.1 d_{z 2}{ }^{3}\left(1-\beta^{4}\right)=0.094 x_{6}^{3}, \beta=0.5$;

$\left[\sigma_{-1}\right]$ - the allowable deflection of the shaft, $\sigma_{-1}=69 \mathrm{MPa}$.

Then finished, the bending strength of drive shaft was

$$
g_{17}(x)=\frac{1}{x_{5}^{3}} \sqrt{\frac{3.34 \times 10^{12} x_{4}^{2}}{x_{2}^{2} x_{3}^{2}}+0.2656 \times 10^{12}}-6.9 \leq 0
$$

The bending strength of lord shaft was 


$$
g_{18}(x)=\frac{1}{x_{6}^{3}} \sqrt{\frac{28.31 \times 10^{12} x_{4}^{2}}{x_{2}^{2} x_{3}^{2}}+0.2656 \times 10^{12}}-6.5 \leq 0
$$

\section{Optimization Calculation Results for Hydraulic Drive Head Parameters}

This optimization problem was adopted in the method of Matlab7.0 Optimization Toolbox. As the table 2 shows that the optimization results gained by objective function (3) and constraint condition (4) $-(28)$.

Tab. 2 The optimization results

\begin{tabular}{|c|c|c|c|}
\hline Parameter & Variant & Initial values & Optimal values \\
\hline The large gear tooth width $b$ & $x_{1}$ & 100 & 190.94 \\
\hline The small gear tooth number $Z_{1}$ & $x_{2}$ & 40 & 35.36 \\
\hline Mode number m & $x_{3}$ & 5 & 6 \\
\hline The supported shaft span length $l$ & $x_{4}$ & 300 & 295.94 \\
\hline Drive shaft diameter $d_{\mathrm{z} 1}$ & $x_{5}$ & 50 & 100 \\
\hline Lord shaft diameter $d_{\mathrm{z} 2}$ & $\mathrm{x}_{6}$ & 150 & 130 \\
\hline
\end{tabular}

\section{Conclusions}

In order to ensure the gear minimum volume and compact structure, the paper set reasonable objective function, parameter and constraints according to the drill known parameters of gear reducer optimized by Matlab which has the powerful calculation function. This optimized method could reduce the workload of program design and provide basic reference for drive head design. It has been verified by the test, selecting the Matlab sequential quadratic programming as the optimization algorithm can improve computation efficiency and ensure the accuracy.

\section{References}

[1] Han,s.p. A Globally Convergent Method for Nonlinear progranmming.Journal of Optimization Theory and Applications, Vol.22,P.297,1997.

[2] Havard Julsrud Harge. Surver of Sofetware Safetype. Norwegian University of Science and Technology[J],2001(11),45-60.

[3] Zhu, C.-C.,Lu, B.,Song, C.-S.,Qin, D.-T.Dynamic analysis of a heavy duty marine gearbox with gear mesh coupling. Proceedings of the Institution of Mechanical Engineers, Part C: Journal of Mechanical Engineering Science . 2009.

[4] Calculation of load capacity of spur and helical gears. ISO6336-1.

[5] William G.Riel. Apparatus and Method for Modified Horizontal directional drilling assembly, United States Patent: US7318491B2. 2008. 